\begin{tabular}{|c|}
\hline CULTURE AND COSMOS \\
www.CultureAndCosmos.org \\
Editor Nicholas Campion \\
Vol. 18 No. 1 Spring/Summer 2014 ISSN 1368-6534 \\
Published in Association with \\
The Sophia Centre for the Study of Culture in Cosmology, \\
University of Wales Trinity Saint David \\
http://www.uwtsd.ac.uk/sophia/ \\
School of Archaeology, History and Anthropology \\
http://www.uwtsd.ac.uk/aha/ \\
\hline
\end{tabular}

\title{
Editorial
}

The Universe as Uncertainty and Action

A current widely-used astronomy textbook by Roger Freedman, Robert Geller and William Kaufmann declares that 'it is this [astronomers'] search for understanding that makes science more than merely a collection of data, and elevates it to one of the great adventures of the human mind'. In partial support of this claim the authors quote Einstein's statement that 'The eternal mystery of the world is its comprehensibility'.2 A search of the web reveals a number of sites which discuss what Einstein meant by this statement, although usually without coming to a particular conclusion. However, a check of the original source, Einstein's essay 'Physics and Reality', reveals that he did not actually directly write the words attributed to him as his opinion. ${ }^{3}$ What he really wrote was slightly different and made careful use of quotation marks: 'One may say "the eternal mystery of the world is its comprehensibility". 4 By carefully enclosing the statement on comprehensibility in double quotation marks, he suggested that, while one may say that the world is comprehensible, equally one may say that it is not. He also deliberately referenced the language of revealed religion

\footnotetext{
${ }^{1}$ Roger A. Freedman, Robert M. Geller and William J. Kaufmann III, Universe, | tenth edition (Basingstoke: W.H. Freeman and Company, 2014), p. 15.

${ }^{2}$ Freedman, Geller and Kaufmann, Universe, p. 15.

3 Albert Einstein, 'Physics and Reality', 1936, in Albert Einstein, Out of My

Later Years (New York: Philosophical Library, 1956), pp. 62-104.

${ }^{4}$ Einstein, 'Physics and Reality', p. 64.
} 
by describing 'the fact that it [the universe] is comprehensible is a miracle'. 5

The context for Einstein's article was the extent to which the previously rigid foundations of science had become problematic under the twin assault of relativity and quantum mechanics. Einstein's text, though, is similarly problematic, and he attempted simultaneously to assert the right of the physicist to comment on a range of disciplines in which they have no expertise, such as philosophy and psychology, but also implied, by contrast, that the entire universe is not comprehensible: even though he insisted that the material world can be investigated, he also conceded that 'we shall never understand' our ability to construct some kind of order in our understanding of the world ${ }^{6}{ }^{6}$ There is therefore a limit to what we can comprehend; the world is comprehensible but not understandable. This paradox runs through Einstein's argument. For example, he argues that a set of rules for investigation the universe must be stated, and they must be rigid in order for investigation to proceed. Yet, at the same time, these rules of investigation can only ever be arbitrary and provisional - 'the fixation will never be final', he wrote. ${ }^{7}$ Einstein was emotionally attached to the idea that the universe is completely comprehensible, yet clearly struggling with the uncertain consequences of relativity and quantum mechanics.

Freedman, Geller and Kaufmann acknowledge the ambivalent nature of Einstein's statement on comprehensibility. The three authors conclude that 'It [the search for understanding of the universe] will continue as long as there are mysteries in the universe'. ${ }^{8}$ The universe is therefore comprehensible in theory, but we do not comprehend it now.

The problem of the limits to the comprehensibility of the universe has a long literary lineage. In 1844 Robert Chambers included the following words in his seminal work on evolution:

The mind fails to form an exact notion of a portion of space so immense; but some faint idea of it may be obtained from the fact, that, if the swiftest race-horse ever known had begin to traverse it, at

\footnotetext{
${ }^{5}$ Einstein, 'Physics and Reality', p. 64.

${ }^{6}$ Einstein, 'Physics and Reality', p. 64.

${ }^{7}$ Einstein, 'Physics and Reality', p. 64.

${ }^{8}$ Freedman, Geller and Kaufmann, Universe, p. 15.
} 
full speed, at the time of Moses, he would only as yet accomplished half his journey. ${ }^{9}$

Chambers' contemporary, the philosopher and historian Thomas Carlyle had a solution to the problem of the unknowability of the universe. Even though we can never know everything, at least we can act in the here and now, liberating ourselves and reforming society, making a better world. In his first great essay, 'Signs of the Times', Carlyle wrote,

On the whole, as this wondrous planet, Earth, is journeying with its fellows through Infinite Space, so are the wondrous destinies embarked on it journeying through Infinite Time, under a higher guidance than ours. For the present, as our astronomy informs us, its path lies towards Hercules, the constellation of Physical Power: but that is not our pressing concern. Go where it will, the deep Heaven will be around it. Therein let us have hope and sure faith. To reform a world, to reform a nation, no wise man will undertake: and all but foolish men know, that the only solid, though a far slower reformation, is what each begins and perfects on himself. ${ }^{10}$

'Our grand business', Carlyle concluded, 'undoubtedly is, not to see what lies dimly at a distance, but to do what lies clearly at hand'. ${ }^{11}$

\section{The Current Issue}

This issue of Culture and Cosmos contains a range of articles spanning the journal's remit - Cultural Astronomy and Astrology. César Esteban explores theoretical issues in archaeoastronomy, drawing on his personal experience as an astrophysicist who has engaged with archaeology and arguing for the importance of landscape archaeology within archaeoastronomical research. Ronald Hutton's paper takes an entirely different perspective. As a historian, Hutton examines the extent to which

\footnotetext{
${ }^{9}$ Chambers, Robert, Vestiges of the Natural History of Creation and Other Evolutionary Writings (1844; Chicago: University of Chicago Press, 1994), pp. 1-2.

${ }^{10}$ Thomas Carlyle, 'Signs of the Times', Edinburgh Review 49 (1829), p. 441. See also Lawrence Poston, 'Millites and Millenarians: The Context of Carlyle's "Signs of the Times"', Victorian Studies 26, no. 4 (Summer 1983), pp. 381-406, p. 406; also see http://www.victorianweb.org/authors/carlyle/signs1.html [accessed 18 Juky2014].

${ }^{11}$ Carlyle, 'Signs of the Times', p. 406.
} 
modern historians have projected their assumptions on to the past, finding, for example, evidence for the worship of a mother Goddess in British megalithic culture. Esteban is an astrophysicist and Hutton is a historian but they share an insistence on critical rigour and a rejection of comfortable assumptions.

Nick Kollerstrom represents the history of astrology, examining Galileo's connection with an apocalyptic astrological text. Clive Davenhall explores an equally curious footnote in the history of modern astronomy: the activities of the German showman Dr Katterfelto, who claimed to have made astronomical discoveries from his balloon. Lastly we include an interview with the distinguished print-maker and painter Geoff MacEwan, following an exhibition of his work inspired by Dante's Divine Comedy at the Christ Church Picture Gallery in Oxford.

Dr Nicholas Campion, Sophia Centre for the Study of Cosmology in Culture, School of Archaeology, History and Anthropology, University of Wales Trinity Saint David. 